\title{
Antagonists of embryo-derived platelet-activating factor act by inhibiting the ability of the mouse embryo to implant*
}

\author{
N. R. Spinks, J. P. Ryan and C. O’Neill \\ Human Reproduction Unit, Royal North Shore Hospital of Sydney, St Leonards, NSW 2065, \\ Australia
}

\begin{abstract}
Summary. This study utilized the transfer of preimplantation embryos to pseudopregnant mice to determine whether PAF-antagonists act primarily on the maternal or embryonic components of implantation. The first experiment used reciprocal embryo transfers, in which blastocysts from mice treated with PAF antagonist (SRI 63-441) or saline (controls), from Days 1 to 4 of pregnancy, were transferred to Day-3 pseudopregnant recipients which were also treated with SRI 63-441 or saline on Days $1-4$ of pregnancy. The antagonist $(40 \mu \mathrm{g})$ was administered at 16:00 h on Day 1 and at 09:00 $\mathrm{h}$ on Days 2-4 of pregnancy. The percentage of the transferred embryos which implanted was determined on Day 8 of pregnancy. Treatment of the recipient or the donor female with SRI 63-441 resulted in a reduction in implantation rate, from a control level of $45 \%$ to $33.8 \%$ or $34.7 \%$ ( $P<0.0002, P<0.007)$ respectively. These results suggest that the PAF antagonist affected implantation at the embryonic and maternal levels. However, when the blastocysts were transferred to Day-4 pseudopregnant recipients, treatment of the donor female had a dramatic effect on the implantation rate, resulting in a reduction of $64 \%$ (from $40 \%$ to $14.3 \%, P<0.04$ ), while treatment of the recipient female had no significant effect. In this later experiment the transferred embryos were exposed to the recipient uterine environment for a shorter period before implantation. These results suggest that PAF antagonists affected implantation at the embryonic level and did not adversely affect maternal physiology. Treatment of pseudopregnant females with PAF antagonist failed to inhibit the deciduogenic response to an intrauterine instillation of paraffin oil, while supplementing embryo culture medium with iloprost, SRI 63-441 or WEB 2086 caused a marked and dose-dependent inhibition of trophoblast outgrowth by blastocysts in vitro. These results were consistent with PAF antagonists having actions at the embryonic rather than the maternal level and support previous suggestions that embryo-derived PAF acts as an essential autocrine growth factor for the early embryo.
\end{abstract}

Keywords: PAF; PAF antagonists; implantation; embryo; endometrium; autocrine growth factor; mouse

\section{Introduction}

Mouse and human preimplantation embryos produce a platelet-activating factor (PAF) which is homologous to 1-o-alkyl-2-acetyl-sn-glyceryl-3-phosphocholine (O'Neill, 1985a, b; Collier et al., 1988). The production of embryo-derived PAF by human embryos fertilized in vitro correlated with their pregnancy potential (O'Neill \& Saunders, 1984; O'Neill et al., 1987), suggesting that its production is necessary for the establishment of pregnancy. Furthermore, embryo-derived PAF

*Reprint requests to Dr C. O’Neill. 
activity was essential for the establishment of pregnancy in the mouse since iloprost (ZK 36374; Schering AG, Berlin, FRG), a stable analogue of prostacyclin and a general inhibitor of platelet activation (Ylitalo et al., 1984), and SRI 63-441 (Sandoz Research Institute, East Hanover, NJ, USA), a specific PAF-receptor antagonist (Handley et al., 1986), inhibited implantation in the mouse in a dose-dependent manner (Spinks \& O'Neill, 1987). This inhibition was overcome by the simultaneous administration of PAF-acether (Spinks \& O'Neill, 1988). Inhibition of implantation was not due to embryo toxicity of the antagonists, or to the disruption of the luteal-phase endocrine profile. These agents acted to prevent the initiation of implantation rather than induce the resorption of implanted embryos.

These inhibitors could have inhibited implantation by acting to prevent maternal and/or embryonic participation in implantation. This report examines at what level embryo-derived PAF exerts its role in implantation by (i) studying the effects of PAF antagonists on embryo donors and/ or recipients in a series of reciprocal embryo transfer experiments, (ii) assessing the effects of PAF antagonists on the sensitivity of the uterus to an artificial decidual stimulus, and (iii) monitoring the ability of mouse blastocysts to undergo trophoblast outgrowth in vitro in media supplemented with PAF antagonists.

\section{Materials and Methods}

\section{Experimental design}

To assess whether the PAF antagonist, SRI 63-44I, was affecting implantation at the maternal or embryonic levels a $2 \times 2$ factorial design embryo transfer experiment was conducted. Blastocysts were collected from donors treated with SRI 63-441 or with calcium- and magnesium-free Dulbecco's phosphate-buffered saline (PBS) $(8 \cdot 2 \mathrm{~g} \mathrm{NaCl}, 0 \cdot 2 \mathrm{~g}$ $\mathrm{KCl}, 1.15 \mathrm{~g} \mathrm{Na}_{2} \mathrm{HPO}_{4}$ and $0.2 \mathrm{~g} \mathrm{KH}_{2} \mathrm{PO}_{4}$ per litre) for the first 4 days of pregnancy. Embryos were transferred to Day-3 pseudopregnant recipients (Day $1=$ day of mating with vasectomized male) which were treated with SRI 63-441 or PBS for 4 days. A second experiment was undertaken with the exception that embryos were synchronously transferred to Day-4 recipients. This was done to minimize the time that embryos remained in the recipient uterus before the expected time of implantaton.

The effect of PAF antagonist on the decidual cell reaction in response to an artificial decidual stimulus, and on blastocyst trophoblast outgrowth in vitro was also studied.

\section{Effects of PAF-antagonists on the implantation rates of transferred blastocysts}

PAF-antagonist. A stock solution of $500 \mu \mathrm{g}$ SRI $63-441 / \mathrm{ml}$ was prepared in PBS and stored at $4 \mathrm{C}$. Working dilutions were prepared in PBS.

Embryos. Random-bred Swiss albino mice, 5-6 weeks old, of the Quackenbush strain (Department of Veterinary Physiology, University of Sydney, NSW, Australia) were superovulated with 10 i.u. PMSG (Folligon: Intervet, Boxmeer, The Netherlands), intraperitoneal injection (i.p.), followed $48 \mathrm{~h}$ later by 10 i.u. hCG (Chorulon: Intervet). The mice were paired with males of proven fertility, and the presence of a vaginal plug the next morning indicated Day 1 of pregnancy. The mice received $40 \mu \mathrm{g}$ SRI 63-441 (i.p.) in $200 \mu \mathrm{l} \mathrm{PBS} / 30 \mathrm{~g}$ body weight or the vehicle alone at 16:00 h on Day 1 and 09:00 h on Days 2-4. These animals were autopsied on Day 4 and the uteri were fushed with Hepes-buffered HTF medium (Quinn et al., 1985) supplemented with $3 \mathrm{mg}$ bovine serum albumin/ml (Pentex, bovine albumin, crystallized: Miles Diagnostic, Kankakee, IL, USA). Blastocysts were cultured in medium for $<2 \mathrm{~h}$ before transfer to pseudopregnant recipients.

Recipients. Ovulation was synchronized (3 i.u. PMSG and 3 i.u. hCG) in 8-9-week-old mice and the females were paired with vasectomized males of proven infertility. The presence of a vaginal plug the next morning indicated Day 1 of pseudopregnancy. The mice received SRI 63-441 or PBS as described above. On Day 3 or Day 4 of pseudopregnancy the mice were anaesthetized with pentabarbitone sodium (Bomac Laboratories, Asquith, NSW, Australia). The uteri were exteriorized through a paramedial-dorsal incision and 10 blastocysts were transferred to each uterine horn in $2.0 \mu \mathrm{l}$ medium via a finely drawn pipette inserted through a hole made with a fine-gauge needle in the anterior of the uterine horn, just below the utero-tubual junction. These animals were autopsied on Day 8 and the number of implantation sites was recorded.

\section{Effects of PAF antagonist on the uterine response to a decidual stimulus}

Females, 8-9 weeks old, were induced to ovulate ( 3 i.u. PMSG and 3 i.u. hCG) and were placed with vasectomized males. Females with vaginal plugs were treated with SRI 63-44I or PBS on Days I-4 as previously described. On Day 4 of 
pseudopregnancy the mice were anaesthetized and $10 \mu$ l of heavy liquid paraffin oil (BDH Chemicals Ltd, Poole, UK) were injected into the uterine lumen of the left or right uterine horn using the same procedure as for embryo transfer. On Day 5 the uteri were excised and weighed.

\section{Effect of PAF antagonist on trophoblast outgrowth in vitro}

Embryos. Mice were superovulated with 10 i.u. PMSG and 10 i.u. hCG. Two-cell embryos were collected by flushing oviducts with Hepes-buffered medium at 10:00 h on Day 2 of pregnancy. Embryos were cultured for $72 \mathrm{~h}$, in groups of 10 , in $10 \mu \mathrm{l}$ droplets of protein-free HTF medium (Quinn et al., 1985) under paraffin oil. After $72 \mathrm{~h}, 60-80 \%$ of embryos had developed to expanded blastocysts. All blastocysts of normal morphology were pooled and transferred to fresh media for the outgrowth experiment.

Blastocyst outgrowth. Fetal calf serum (FCS: Flow Laboratories Ltd, Irvine, Ayrshire, UK) was stored at $-20^{\circ} \mathrm{C}$. On the evening before culture the serum was thawed, heat-inactivated at $56^{\circ} \mathrm{C}$ for $20 \mathrm{~min}$ and then diluted to a final concentration of $1 \%(\mathrm{v} / \mathrm{v})(\mathrm{MEM} / \mathrm{FCS})$ with Eagle's minimal essential medium (MEM: Flow Laboratories Ltd) supplemented with $26 \cdot 2 \mathrm{~mm}$-sodium bicarbonate (Ajax Chemicals, Sydney, NSW, Australia).

Three antagonists were used in the study, iloprost (Schering AG, Berlin, FRG), SRI 63-441 (Sandoz Research Institute, East Hanover, NJ, USA) and WEB 2086 (Boehringher Ingelheim, KG, Ingelheim/Rhein, FRG). Working concentrations were prepared by serial dilution in MEM/FCS. The medium was set up as $10 \mu \mathrm{l}$ drops under paraffin oil (BDH Chemicals Ltd) in plastic trays (Falcon Plastics, Cockeysville, MD, USA). Between 4 and 10 blastocysts were added per drop at 09:00-11:00 h. The embryos were cultured for $72 \mathrm{~h}$ and development was monitored by inverted phase-contrast microscopy.

\section{Statistical analysis}

The results presented in Tables 1,2 and 4 were analysed by logistic regression on the proportions of the transferred embryos which implanted (Breslow et al., 1983). Data on the uterine sensitivity to an artificial decidual stimulus (Table 3) were analysed using a nested mixed model analysis of variance (Snedecor \& Cochran, 1981).

\section{Results}

\section{Effects of PAF antagonist on the implantation rates of transferred blastocysts}

A significant reduction in the implantation rate of blastocysts transferred to Day 3 pseudopregnant recipients occurred when either the donor $(22.9 \%, P<0.007)$ or the recipient $(24.9 \%$, $P<0.0002$ ) was treated with SRI 63-441 (Table 1). The greatest reduction $(42 \cdot 7 \%)$ was observed when both the donor and the recipient were treated, although the effects were additive, not synergistic.

Table 1. The percentage of blastocysts transferred from female mice, treated with SRI 63-441 or PBS, which implanted in Day-3 pseudopregnant females treated with SRI 63-441 or PBS

\begin{tabular}{|c|c|c|}
\hline \multirow{2}{*}{$\begin{array}{l}\text { Treatment } \\
\text { of donors }\end{array}$} & \multicolumn{2}{|c|}{ Treatment of recipients } \\
\hline & Control & SRI 63-44I \\
\hline Control & $45.0 \%(14)$ & $33.8 \%(12)$ \\
\hline SRI 63-441 & $34 \cdot 7 \%(16)$ & $25 \cdot 8 \%(13)$ \\
\hline
\end{tabular}

A dramatic difference in implantation rates was observed between the treatment of the donor or the recipient when blastocysts were transferred to Day-4 pseudopregnant recipients (Table 2). Treatment of the recipient female resulted in a small $(13.9 \%, P>0.30)$ reduction in the number of 
transferred blastocysts that implanted, while treatment of the donor female with SRI 63-441 resulted in a much greater $(64.0 \%, P<0.04)$ reduction in the number of blastocysts that implanted.

Table 2. The percentage of blastocysts that implanted after transfer to Day-4 pseudopregnant recipient mice when either the donor or the recipient females were treated with the PAF antagonist (SRI 63-441)

\begin{tabular}{lcclcc}
\hline & \multicolumn{2}{c}{ Treatment of donors } & & \multicolumn{2}{c}{ Treatment of recipients } \\
\cline { 2 - 3 } \cline { 5 - 6 } & Control & SRI 63-441 & & Control & SRI 63-441 \\
\hline Implantation rate (\%) & $40 \cdot 0$ & $14 \cdot 4^{*}$ & & $42 \cdot 3$ & $36 \cdot 4$ \\
No. of mice & 11 & 9 & & 11 & 11 \\
\hline
\end{tabular}

${ }^{*}$ Logistic regression established a significant $(P<0.04)$ effect of treating the donor female with SRI 63-44I.

\section{Effects of PAF antagonist on uterine receptivity to a decidual stimulus}

In the PAF antagonist-treated and the control pseudopregnant mice, intrauterine injection of an oil droplet on Day 4 of pseudopregnancy resulted in an increase in uterine weight, measured on Day 5 of pseudopregnancy, of 37 and $40 \%$ respectively (Table 3 ). Oil therefore induced a decidual response $(P<0.009)$ irrespective of treatment of females with a PAF antagonist throughout the preimplantation stage.

Table 3. The effect of the PAF antagonist (SRI 63-44l) on the uterine sensitivity to an artificial decidual stimulus (paraffin oil) injected into the uterine lumen of mice on Day 4 of pseudopregnancy

\begin{tabular}{|c|c|c|c|c|}
\hline & \multicolumn{4}{|c|}{ Treatment } \\
\hline & \multicolumn{2}{|c|}{ SRI 63-441 } & \multicolumn{2}{|c|}{ PBS } \\
\hline & Oil & PBS & Oil & PBS \\
\hline $\begin{array}{l}\text { Mean } \pm \text { s.e.m. } \\
\text { uterine wt }(\mathrm{mg})\end{array}$ & $74 \cdot 9 \pm 7 \cdot 3$ & $54 \cdot 6 \pm 3 \cdot 4$ & $72.7 \pm 13.5$ & $51 \cdot 7 \pm 3 \cdot 5$ \\
\hline No, of animals & 8 & 8 & 8 & 8 \\
\hline
\end{tabular}

\section{Effect of PAF antagonist on trophoblast outgrowth in vitro}

The functional PAF antagonist iloprost was a potent inhibitor of blastocyst outgrowth in vitro, causing a marked dose-related effect. No obvious inhibition occurred at $10^{-5} \mu \mathrm{g} / \mathrm{ml}$ but $1 \mu \mathrm{g} / \mathrm{ml}$ resulted in total inhibition of outgrowth (Table 4). A further 10 times increase in concentration $(10 \mu \mathrm{g} / \mathrm{ml})$ also resulted in no outgrowth. Similar results occurred for the specific PAF-receptor 
Table 4. Blastocyst outgrowth in medium containing $1 \%$ FCS with various concentrations of PAF antagonists

\begin{tabular}{|c|c|c|c|c|c|c|c|c|}
\hline \multicolumn{3}{|c|}{ Iloprost } & \multicolumn{3}{|c|}{ SRI 63-44l } & \multicolumn{3}{|c|}{ WEB 2086} \\
\hline $\begin{array}{l}\text { Dose } \\
(\mu \mathrm{g} / \mathrm{ml})\end{array}$ & $\begin{array}{l}\text { Outgrowth } \\
(\%)\end{array}$ & No. & $\begin{array}{l}\text { Dose } \\
(\mu \mathrm{g} / \mathrm{ml})\end{array}$ & $\begin{array}{c}\text { Outgrowth } \\
(\%)\end{array}$ & No. & $\begin{array}{l}\text { Dose } \\
(\mu \mathrm{g} / \mathrm{ml})\end{array}$ & $\begin{array}{c}\text { Outgrowth } \\
(\%)\end{array}$ & No. \\
\hline - & - & - & 20 & $0 \pm 0$ & 20 & - & - & - \\
\hline 10 & $0 \pm 0$ & 30 & 10 & $0 \pm 0$ & 10 & 10 & $0+0$ & 33 \\
\hline l & $0 \pm 0$ & 35 & 1 & $19 \pm 8$ & 25 & 1 & $0 \pm 0$ & 30 \\
\hline $10^{-2}$ & $21 \pm 12$ & 28 & $10^{-2}$ & $45 \pm 11$ & 35 & $10^{-2}$ & $5 \pm 10$ & 35 \\
\hline $10^{-3}$ & $28 \pm 13$ & 30 & $10^{-3}$ & $71 \pm 15$ & 30 & $10^{-3}$ & $25 \pm 13$ & 35 \\
\hline $10^{-4}$ & $32 \pm 15$ & 25 & & & & $10^{-4}$ & $67 \pm 6$ & 30 \\
\hline $10^{-5}$ & $55 \pm 14$ & 25 & & & & & & \\
\hline Control & $53 \pm 17$ & 30 & Control & $65 \pm 14$ & 45 & Control & $65 \pm 8$ & 32 \\
\hline
\end{tabular}

Values are mean \pm s.e.m.

antagonists SRI 63-441 and WEB 2086, with both antagonists completely inhibiting outgrowth at a dose of $10 \mu \mathrm{g} / \mathrm{ml}$.

\section{Discussion}

This study confirms previous observations (Spinks \& O'Neill, 1987, 1988; Acker et al., 1988) that PAF-specific receptor antagonists inhibit implantation. However, no definitive role for embryoderived PAF in the process of implantation was previously demonstrated. PAF is capable of causing vasodilatation and increased vascular permeability (Wedmore \& Williams, 1981; Humphrey et al., 1982) and mediates other events associated with inflammatory reactions (McManus, 1986). Therefore, a role for PAF in the maternal events of implantation is intuitively attractive since the earliest stages of implantation and the decidual reaction both induce enhanced vascular permeability (Psychoyos, 1961) and have striking similarities to an inflammatory reaction (Kennedy \& Armstrong, 1980). However, PAF also is a potent activator of cellular metabolism and activity through its receptor mediated stimulation of phospholipase $\mathrm{C}$, leading to the breakdown of phosphatidylinositol (Mauco et al., 1983) and the formation of diacylglycerol (Mauco et al., 1983) and inositol triphosphate (Berridge, 1984). These intracellular mediators led to the activation of target cells through the mobilization of $\mathrm{Ca}^{2+}$ and phosphorylation of proteins (Nishizuka, 1984). PAF might therefore act as a proinflammatory mediator at the implantation site or act to enhance cellular metabolic activity, including embryonic activity associated with implantation.

To assess whether embryo-derived PAF exerted its effect on implantation at the embryonic or maternal level, blastocysts were collected from females treated with PBS or PAF-antagonist, and transferred to Day-3 pseudopregnant recipients treated with PBS or PAF-antagonist. SRI 63-441 affected both the embryos from donor females and the ability of recipients to allow implantation. However, statistical analysis revealed that when both the donor and recipient were treated the effect on implantation was only additive and not synergistic (Table 1), suggesting that the antagonist affected implantation by similar mechanisms in the donor and recipient. There is, however, a clear limitation in this experimental design. Although asynchronous transfers of mouse embryos are claimed to give the best results (McLaren \& Michie, 1956), the implantation of blastocysts transferred to the uterus of Day-3 recipients is delayed for at least $24 \mathrm{~h}$. Therefore, naive blastocysts transferred to antagonist-treated females are exposed to the antagonist for $24 \mathrm{~h}$ before implantation. This clearly compromises the experimental design and does not allow consideration of whether the agents act at a maternal or embryonic level.

To overcome this objection a second series of transfers was performed to Day-4 recipients. Such synchronous transfers resulted in a similar implantation rate in controls as did asynchronous 
transfers. These results demonstrated that SRI 63-441 had its major effect when the animals which acted as embryo donors were treated. This resulted in a $64 \%$ decrease $(P<0.04)$ in the implantation rate. By comparison, there was only a $14 \%$ reduction $(P>0.05)$ in implantation rate when only the recipients were treated, even though the recipient was treated up until just before the initiation of implantation. This suggests that exposure of embryos to the antagonist for a significant period before the initiation of implantation is required for its inhibition. The results of the Day-3 (Table 1) transfers suggest that exposure for the $24 \mathrm{~h}$ before implantation was sufficient. This result also indicates that PAF antagonists had no critical effect on the maternal preparation for implantation, hence their action was exerted either directly or indirectly upon the embryo.

Arachidonic acid metabolites are clearly involved in implantation and PAF is known to mediate their production and actions (O'Flaherty et al., 1981; Shaw et al., 1981; Jouvin-Marche et al., 1982). Pakrasi et al. (1985), Malathy et al. (1986) and Tawfik et al. (1987) observed increases in intrauterine concentrations of prostaglandins (PGs) and leukotrienes in rats at the time of embryo implantation and suggested that these metabolites of arachidonic acid mediate the earliest stage of embryo implantation. PGs of the E series cause vasodilatation whereas leukotrienes act by increasing the vascular permeability characteristic of implantation. Further, PAF induces the formation of arachidonic acid (O'Flaherty et al., 1981; Shaw et al., 1981; Jouvin-Marche et al., 1982) and modifies PG production by the human endometrium (Smith \& Kelly, 1988). A role for PAF as a mediator of the decidual reaction was suggested by Acker et al. (1988) who reported that direct instillation of PAF into the rat uterine lumen induced a decidua-like reaction and that this was inhibited by the PAF receptor antagonist BN 52021. However, a role for PAF in such responses was not supported in the present study since treatment of embryo recipients (Table 2) alone had no significant effect on the implantation rate and pseudopregnant animals treated with SRI 63-441 were still responsive to an artificial decidual stimulus (Table 3).

A wide variety of artificial stimuli, both chemical and physical, induce this reaction in mice and rats. However, Weitlauf (1987) observed that when the stimulation for decidualization was a normal implanting embryo the pattern of protein synthesis was different from that when an intrauterine thread was used. This suggests that the uterus can distinguish between these two deciduogenic stimuli, and so study of artificially induced decidual reactions as a model for the maternal phase of implantation must be interpreted with caution. Despite these limitations, the results of this study show that PAF antagonists cannot prevent the elicitation of the decidual reaction following induction by an artificial stimulus and that embryos transferred to recipient females treated with PAF antagonist can elicit a normal decidual response and undergo implantation. Presumably, in such circumstances those embryos produced PAF. This experiment suggests, therefore, that PAF is not likely to be the initial decidual stimulus. This is consistent with the observations that PAF instillation into the uterus of mice could not induce deciduoma (Milligan \& Finn, 1990) but in contrast with results of Acker et al. (1988) and may represent a difference between the rat and mouse. Not only is PAF unlikely to be the signal initiating the decidual reaction, it is also unlikely to have a major role in its progression. Further, the contragestational action of PAF antagonist was such that the vascular and hence decidual responses to implantation did not occur (Spinks \& O'Neill, 1988), indicating that the agents exerted their effects before the initiation of implantation. PAF antagonists therefore act either directly or indirectly on the embryo to prevent its participation in implantation.

There is now evidence that embryo-derived PAF affects the embryo directly in an autocrine manner. Two-cell mouse embryos exhibit a dose-dependent response to PAF in the oxidative metabolism of lactate (Ryan et al., 1987). The specificity of this response was demonstrated by its prevention with the specific PAF-receptor antagonist SRI 63-441 (J. P. Ryan, unpublished data). Development of 2-cell mouse embryos through to the blastocyst stage during culture in vitro takes 18-24 h longer than in vivo (Bowman \& McLaren, 1970a; Harlow \& Quinn, 1982), results in fewer blastomeres per blastocyst (Bowman \& McLaren, 1970a), reduces the ability of the embryos to implant (Bowman \& McLaren, 1970b) and the production of PAF by these embryos decreases with increasing time in culture (Ryan et al., 1989). Culture of embryos for $72 \mathrm{~h}$ in the presence of PAF, 
however, resulted in blastocysts that (i) exhibited increased oxidative metabolism of lactate above that of controls, (ii) had an increased number of blastomeres per blastocyst, and (iii) were more viable as indicated by their greater ability to implant after transfer (Ryan et al., 1988). PAF therefore has direct effects on the embryo which may be elicited, as in other systems, through receptor-mediated stimulation and activation of target cells.

Such an autocrine role for PAF is consistent with the observations that embryos cultured in vitro, a situation known to reduce the production of PAF (Ryan et al., 1989), results in reduced pregnancy potential. Treatment of embryos in vitro or in vivo with SRI 63-441 and WEB 2086, or the functional antagonist iloprost, inhibited blastocyst outgrowth in vitro (Table 3) but iloprost and SRI 63-441 had no effect on development in vitro or in vivo up to the blastocyst stage (Spinks \& O'Neill, 1988). This suggests that PAF is essential for this major differentiation step of trophoblast outgrowth and therefore for implantation. During the preimplantation stage, therefore, PAF has an autocrine effect on the embryo which enhances metabolic rate, cleavage rate and thus the viability of the embryo. PAF antagonists, however, do not prevent development to the blastocyst stage, suggesting that receptor-mediated responses to PAF are unlikely to be essential up until this time. There appears to be a crucial temporal window at the blastocyst stage where exposure of the embryo to PAF is essential for initiating the events that lead to the production of an invasive trophoblast. It now remains to be determined how embryo-derived PAF exerts such a crucial effect on the embryo. The use of PAF antagonists provides a useful tool for the elucidation of the mechanisms involved.

We thank Dr E. Schillinger (Schering AG, Berlin, FRG) for iloprost; D. Handley (Sandoz Research Institute, East Hanover, NJ, USA) for SRI 63-441; Dr H. Heuer (Boeringher Ingelheim, K.G. Ingelheim/Rhein, FRG) for WEB 2086; and Mr M. Jones for advice on statistical analysis. This work was supported by an NH and MRC grant No. 860550 (C.O'N.). N.R.S. is supported by a RNSH post-graduate scholarship.

\section{References}

Acker, G., Hecquet, F., Etienne, A., Braquet, P. \& MerciaHuerata, J.M. (1988) Role of platelet-activating factor (PAF) in ovoimplantation in the rat: effect of the specific PAF-acether antagonist, BN 52021. Prostaglandins 35, 233-241.

Berridge, M.J. (1984) Inositol triphosphate and diacylglycerol as second messengers. Biochem. J. 220, 693-698.

Bowman, P. \& McLaren, A. (1970a) Cleavage rates of mouse embryos in vivo and in vitro. J. Embryol. exp. Morph. 24, 203-207.

Bowman, P. \& McLaren, A. (1970b) Viability and growth of mouse embryos after in vitro culture fusion. $J$. Embryol. exp. Morph. 23, 693-704.

Breslow, N.E., Lubin, J.H., Marek, P. \& Langholz, B. (1983) Multiplicative models and cohort analysis. $J$. Am. Stat. Ass. 78, 1-12.

Collier, M., O'Neill, C., Ammit, A.J. \& Saunders, D.M. (1988) Biochemical and pharmacological characterization of human embryo-derived platelet activating factor. Human Reprod. 8, 993-999.

Handley, D.A., Tomesch, J.C. \& Saunders, R.N. (1986) Inhibition of PAF-induced systemic responses in the rat, guinea-pig, dog, and primate by the receptor antagonist SRI 63-441. Thromb. Haemost. 56, 40-44.

Harlow, G.M. \& Quinn, P. (1982) Development of preimplantation mouse embryos in vivo and in vitro. Aust. J. biol. Sci. 35, 187-193.
Humphrey, D.M., McManus, L.M., Satouchi, K., Hanahan, D.J. \& Pinckard, R.N. (1982) Vasoactive properties of acetyl glyceryl ether phosphorylcholine and analogues. Lab. Invest. 46, 422-427.

Jouvin-Marche, E., Poitevin, B. \& Benveniste, J. (1982) Platelet-activating factor (PAF-acether), an activator of neutrophil functions. Agents Actions 12, 716-720.

Kennedy, T.G. \& Armstrong, D.T. (1980) The role of prostaglandins in endometrial vascular changes at implantation. In Cellular and Molecular Aspects of Implantation, pp. 349-358. Eds S. R. Glasser \& D. W. Bullock. Plenum Press, New York.

Malathy, P.V., Cheng, H.C. \& Dey, S.K. (1986) Production of leukotrienes and prostaglandins in rat uterus during periimplantation period. Prostaglandins 32, 605-614.

Mauco, G., Chap, H. \& Dauste-Blazy, L. (1983) Plateletactivating factor (PAF-acether) promotes an early degradation of phosphatidylinositol-4,5-biphosphate in rabbit platelets. FEBS Lett. 153, 361-365.

McLaren, A. \& Michie, D. (1956) Studies on the transfer of fertilized mouse eggs to uterine foster mothers. $J$. exp. Biol. 33, 394-416.

McManus, L.M. (1986) Pathobiology of plateletactivating factors. Pathol. Immunopathol. Res. 5, 104-117.

Milligan, S.R. \& Finn, C.A. (1990) Failure of platelet-activating factor (PAF-acether) to induce 
decidualization in mice and failure of antagonists of PAF to inhibit implantation. J. Reprod. Fert. 88, 105-112.

Nishizuka, Y. (1984) The role of protein kinase C in cell surface signal transduction and tumor promotion. Nature, Lond. 308, 693-698.

O'Flaherty, J.T., Wykle, R.L., Mueller, C.H., Lewis, J.C., Waite, M., Bass, D.A., McCall, C.E. \& DeChatelel, L.R. (1981) 1-o-alkyl-sn-glyceryl-3-phosphorlcholines: a novel class of neutrophil stimulants. Am. J. Pathol. 103, $70-79$.

O'Neill, C. (1985a) Examination of the cause of early pregnancy thrombocytopenia in mice. $J$. Reprod. Fert. 73, 567-577.

O'Neill, C. (1985b) Partial characterization of the embryo-derived platelet-activating factor in mice. $J$. Reprod. Fert. 75, 375-380.

O'Neill, C. \& Saunders, D.M. (1984) Assessment of embryo quality. Lancet 2, 1034-1035.

O'Neill, C., Gidley-Baird, A.A., Pike, I.L. \& Saunders, D.M. (1987) Use of a new bioassay for embryo-derived platelet-activating factor as a means of assessing quality and pregnancy potential of human embryos. Fert. Steril. 47, 969-975.

Pakrasi, P.L., Becka, R. \& Dey, S.K. (1985) Cyclooxygenase and lipoxygenase pathways in preimplantation rabbit uterus and blastocysts. Prostaglandins 29, 481-495.

Psychoyos, A. (1961) Perméabilité capillaire et decidualization utérine. C. r. hebd. Séanc. Acad. Sci. Paris 252, 1515-1517.

Quinn, P., Warnes, G.M., Kerin, J.F. \& Kirby, C. (1985) Culture factors affecting the success rate of in vitro fertilizaton and embryo transfer. Ann. N.Y. Acad. Sci. 442, 195-203.

Ryan, J.P., Wiegand, M.H., O’Neill, C. \& Wales, R.G. (1987) In vitro development and metabolism of lactate by mouse embryos in the presence of platelet-activating factor. Proc. Aust. Soc. Reprod. Biol. 19, Abstr. 47.

Ryan, J.P., Spinks, N.R., O'Neill, C. \& Wales, R.G. (1988) Implantation potential and foetal viability of embryos cultured in the presence of platelet-activating factor. Proc. Aust. Soc. Reprod. Biol. 20, Abstr. 47.
Ryan, J.P., Spinks, N.R., O'Neill, C., Ammit, A.J. \& Wales, R.G. (1989) Platelet-activating factor (PAF) production by mouse embryos in vitro and its effects on embryonic metabolism. J. Cell Biochem. 40, 387-395.

Shaw, J.O., Klusick, S.J. \& Hanahan, D.J. (1981) Activation of rabbit platelet phospholipase and thromboxane synthesis by 1-o-hexadecyl/octadecyl2 - acetyl-sn-glyeryl-3 - phosphocholine (platelet activating factor). Biochim. Biophys. Acta 663, 222-229.

Smith, S.K. \& Kelly, R.W. (1988) Effects of plateletactivating factor on the release of PGF-2 $\alpha$ and PGE-2 by separated cells of human endometrium. J. Reprod. Fert. 82, 271-276.

Snedcor, G.W. \& Cochran, W.G. (1981) Statistical Methods. Iowa State University Press, Ames.

Spinks, N.R. \& O'Neill, C. (1987) Embryo-derived PAF activity is essential for the establishment of pregnancy in the mouse. Lancet i, 106-107.

Spinks, N.R. \& O'Neill, C. (1988) Antagonists of embryoderived platelet-activating factor prevent implantation of mouse embryos. J. Reprod. Fert. 84, 89-98.

Tawfik, O.W., Huet, Y.M., Malathy, P.V., Johnson, D.C. \& Dey, S.K. (1987) Release of prostaglandin and leukotrienes from rat uterus is an early oestrogenic response. Prostaglandins 34, 805-815.

Wedmore, C.V.\& Williams, T.J.(1981) Platelet-activating factor (PAF) a secretory product of polymorphonuclear monocytes increases vascular permeability in rabbit skin. Br. J. Pharmacol. 74,916-917.

Weitlauf, H.M. (1987) Implantation associated changes in uterine secreted proteins. Adv. exp. Med. Biol. 230, 207-220.

Ylitalo, P., Kaukinen, S., Seppala, E., Nurmi, A.K., Pessi, T., Krais, T. \& Vapaatalo, H. (1984) Pharmacological effects of Iloprost (ZK 36374), a stable prostacyclin analogue, in man. Biomed. Biochim. Acta 43, S399-S402. 